\title{
Simulation of Thermal Transfer Through the Polyamide Intake Manifold
}

\author{
CORNELIU BIRTOK-BANEASA*, ADINA BUDIUL-BERGHIAN, VIRGINIA ANA SOCALICI, ROBERT BUCEVSCHI \\ Politehnica University of Timisoara, Faculty of Engineering Hunedoara, 5 Revolutiei Str., 331128, Hunedoara, Romania
}

\begin{abstract}
The aim of the present study is to model the steady heat transfer of the engine polyamide intake manifold. Under the condition of a steady flow, the intake manifold wall temperature and the intake air temperature were measured to examine the effect of the thermal boundary layer on the heat transfer. Experimental data is used to generate the numerical model of airflow simulation through the intake manifold.
\end{abstract}

Keywords: intake manifold, intake air, polyamide, numerical simulation

Increasing the use of plastics in designing and revitalizing vehicles in vehicle production will increase the demand for the automotive industry in plastic. Plastic helps car manufacturers reduce their production and assembly costs and produce more attractive and appealing functional designs. The rising demand for vehicles from emerging economies such as China, India and Latin American countries is expected to boost industry. Volatile raw material prices and huge investments in new material research are the major challenges facing industry specialists. Biodegradable plastics such as PHA, PCL and PBS provide a better opportunity for major manufacturers in the machine industry [1,2].

Composites are any combination of polymer matrix and fibrous reinforcement. Glass, carbon, aramid and other fibers provide strength and rigidity, while the polymer matrix (or resin) made of polyester, polyurethane, epoxy, polypropylene, nylon or other resin protects and transfers loads between fibers [3- 7]. This creates a material with attributes superior to the polymer or fiber itself. In recent years, carbon fiber reinforced composites have applied to light vehicles.

The plastics and polymer components were essential for a wide range of advances in today's safety and performance. Today's plastics generally account for $50 \%$ of the volume of a new lightweight vehicle, but less than $10 \%$ of its weight, which makes vehicles lighter and more fuel efficient, which leads to low greenhouse gas emissions. Durable, modern components and polymer composites also help improve passenger safety, and car designers rely on the versatility of plastic materials and polymer composites and the aesthetic possibilities of vehicle design. In addition, many plastic resins are recyclable $[3,5,8]$.

Modern automobile engines' fuel efficiency improvement and reduction of hazardous exhaust gases are becoming more demanding. In regard to those strict regulations, the previous studies [9- 12] developed the technology to reduce the combustion fluctuation and maintain the constant air-to-fuel ratio.

However, the previous studies [2, 13-16] stated that the combustion fluctuation was increased by increasing the variation in the air-to-fuel ratio due to the heat transfer phenomenon of the intake system, in direct connection with the material (PA66, Al alloy) of the intake manifold (fig. 1).

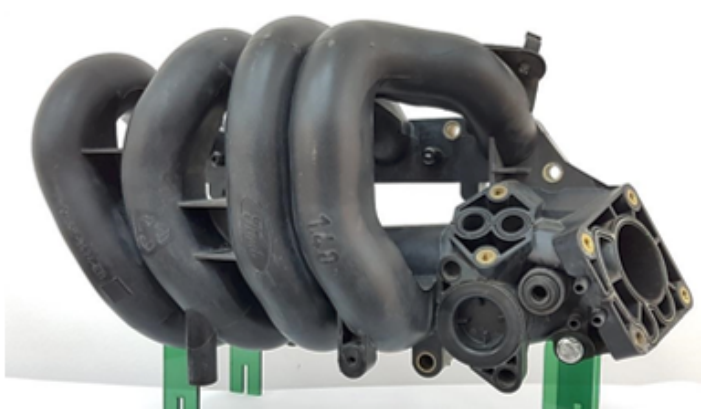

Fig.1. Polyamide intake manifold

\section{Experimental part}

The data required for the numerical simulation model of the thermodynamic processes taking place in the air flow through the intake manifold were obtained with the experimental laboratory equipment specifically designed for this purpose.

The positioning of the experimental stand elements respects the actual intake manifold configuration in the engine compartment relative to the heating source (fig. 2). The stand allows temperature measurements to be made at various points for a Ford Puma 1.4 engine intake manifold made of polyamide (PA 66).

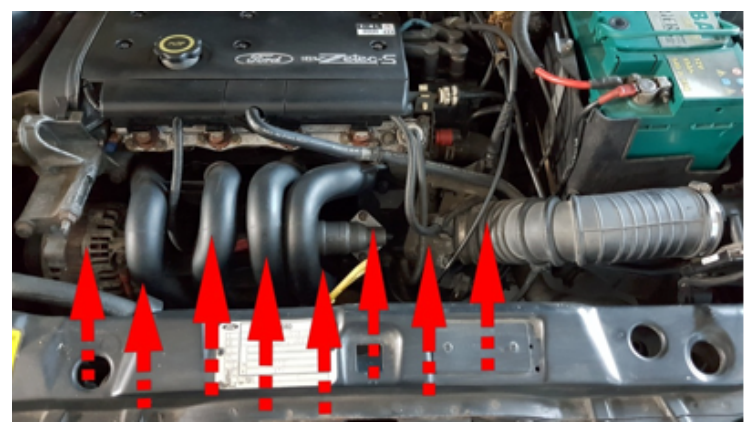

Fig.. 2. Ford Puma 1.4 engine compartment

The experimental stand (fig. 3) contains, a blower (1) and a throttle valve (2) were placed, followed by the intake manifold (3) and a straight pipe region (4). The blower was used to direct intake air into the intake manifold, simulating the supercharging process. Three NiCr-Ni thermocouple sensors were used for temperatures measurements as follows: T1 - outside the intake manifold heated region, measuring the temperature of the air coming from the heat source, 72 - inside of the intake manifold, 


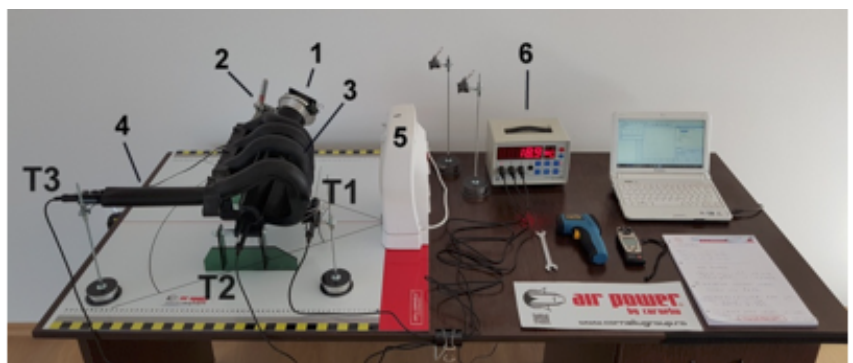

Fig.. 3. General view of experimental setup

measuring the interior wall temperature, T3 - inside the straight pipe region, measuring the temperature of the air that exit the intake manifold. The stand also contains a heating source (5) and a digital temperature indicator (6). Experimental data was acquired with the help of Cassy Lab2 software. The interface of this software is presented in figure 4.a.

The temperature values were taken from second by second to 2500 s until thermal equilibrium was established (fig. 4.b).

After this time the thermal transfer can be considered as a steady state one. In this case, the data necessary for the realization of the numerical simulation model were presented in table 1.
Table 1

EXPERIMENTAL DATA USED FOR THE NUMERICAL SIMULATION MODEL

\begin{tabular}{|l|l|}
\hline Intake air velocity through throttle valve $[\mathrm{m} / \mathrm{s}]$ & 1.7 \\
\hline Heating air velocity $[\mathrm{m} / \mathrm{s}]$ & 1.4 \\
\hline Initial temperature of the intake air $\left[{ }^{\circ} \mathrm{C}\right]$ & 22 \\
\hline Heating air temperature $\left[{ }^{\circ} \mathrm{C}\right]$ & 50 \\
\hline Thermal conductivity of $\mathrm{PA} 66[\mathrm{w} / \mathrm{m} \cdot \mathrm{k}]$ & 0.22 \\
\hline
\end{tabular}

In order to simplify the numerical model, only a part of the intake manifold in the form of a pipe that transports the air to one of the engine cylinders was considered. Thus, the domain of analysis becomes the one shown in figure 5.

The numerical model was developed with ANSYS Multiphysics [17], which is a multi-purpose analysis tool that allows the user to combine the effect of two or more physical phenomena (structural, thermal, electrical, magnetic, electromagnetic, electrostatic, fluid flow).

The following modules were used in the ANSYS package:

-ANSYSDesign Modeler (fig. 6.a) that provides modeling tools specific to simulation requirements, including: the ability to modify existing geometry and tools to create the geometric model.

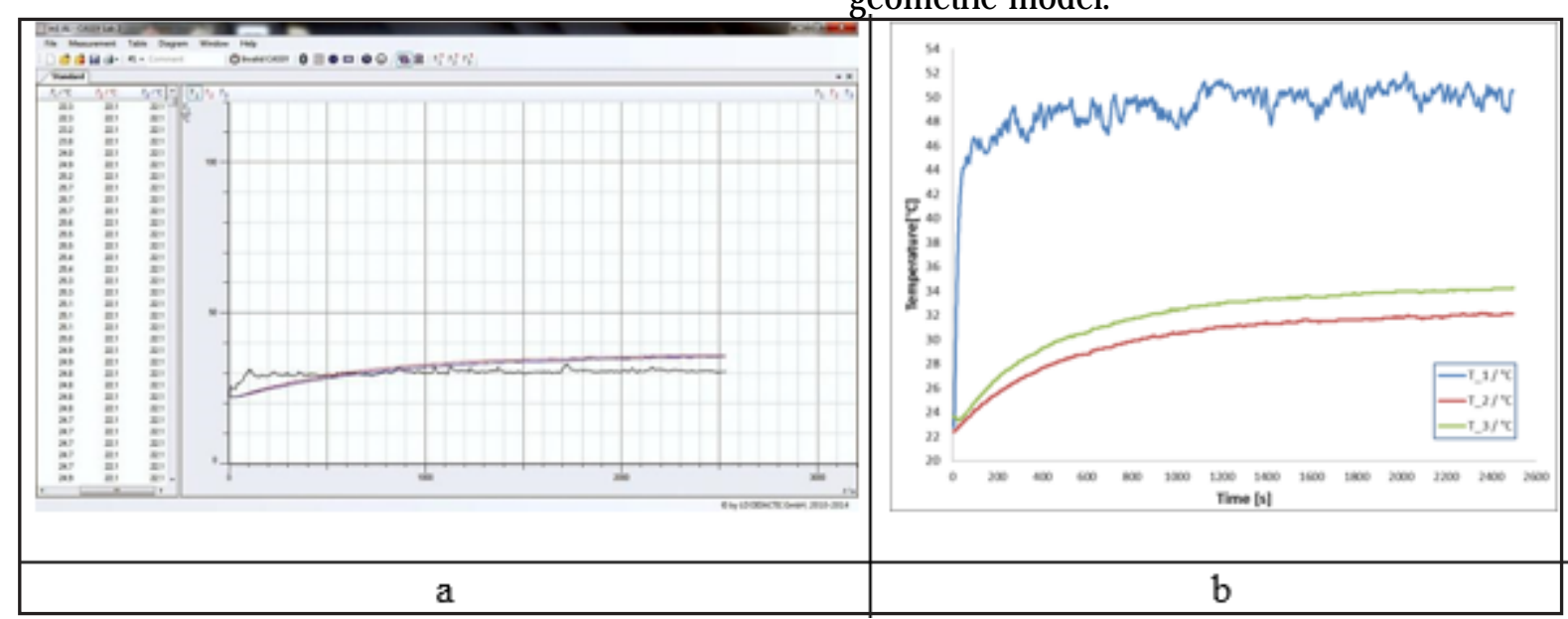

Fig.. 4 CASSY LAB 2 software: $a$ - the interface of the CASSY LAB 2 software; $b$ - the evolution of temperatures

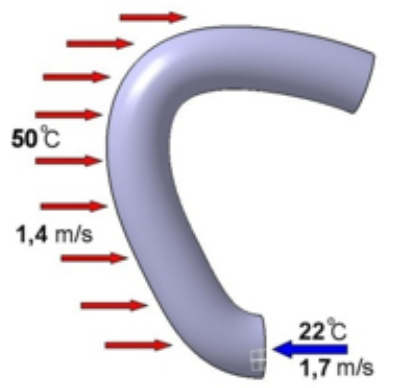

Fig.. 5. The domain of analysis with boundary conditions

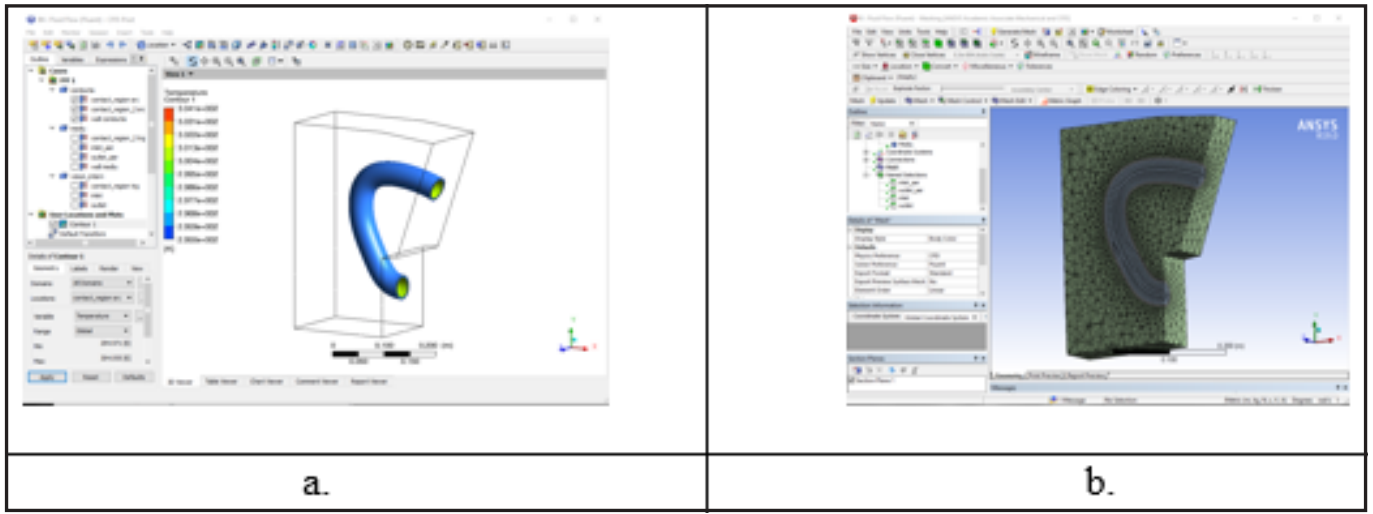

Fig.. 6. ANSYS module interfaces: a - ANSYS Design Modeler, b - ANSYS Meshing 


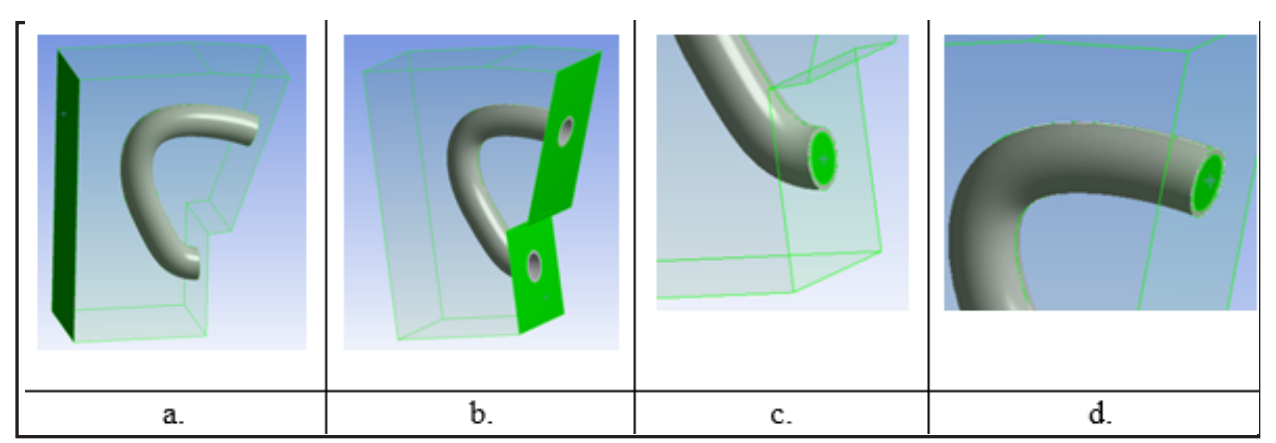

Fig.. 7. Surfaces for data input: a - Surface 1, b - Surface 2, c - Surface 3, d - Surface 4

- ANSYS Meshing (fig. 6.b) provides very complex preprocessing tools with direct connection to solvers. Makes meshing in finite volumes of the domain to be analyzed, depending on the application goal.

- FLUENT is a flexible CFD module, belonging to the ANSYS Multiphysics platform, used for simulations of any complexity. It offers a complete range of physical models that can be used for a wide range of applications across industries.

- CFD Post allows the results to be highlighted both as values and as graphical and imaging [17].

In order to input the data has been defined two surfaces:

Surface 1 - heating air inlet (fig. 7.a); Surface 2 - heating air outlet (fig. 7.b);
Surface 3 - Pipe air inlet (fig. 7.c); Surface 4 - Pipe air outlet (fig. 7.d).

\section{Results and discussions}

After running the simulation, the results in CFD Postwere: -temperature field on a median section plane (fig. 8.a); -current lines depending on temperature (fig. 8.b); -velocity vectors (fig. 9);

-distribution of temperatures on the surfaces (fig. 10).

Analyzing the temperature difference (approx. $3^{\circ} \mathrm{C}$ ) of the incoming air or the exiting pipe, in the case of the stationary thermal regime, we can conclude that the heating of the air entering the engine cylinder is insignificant due to the material from which the pipe is made.
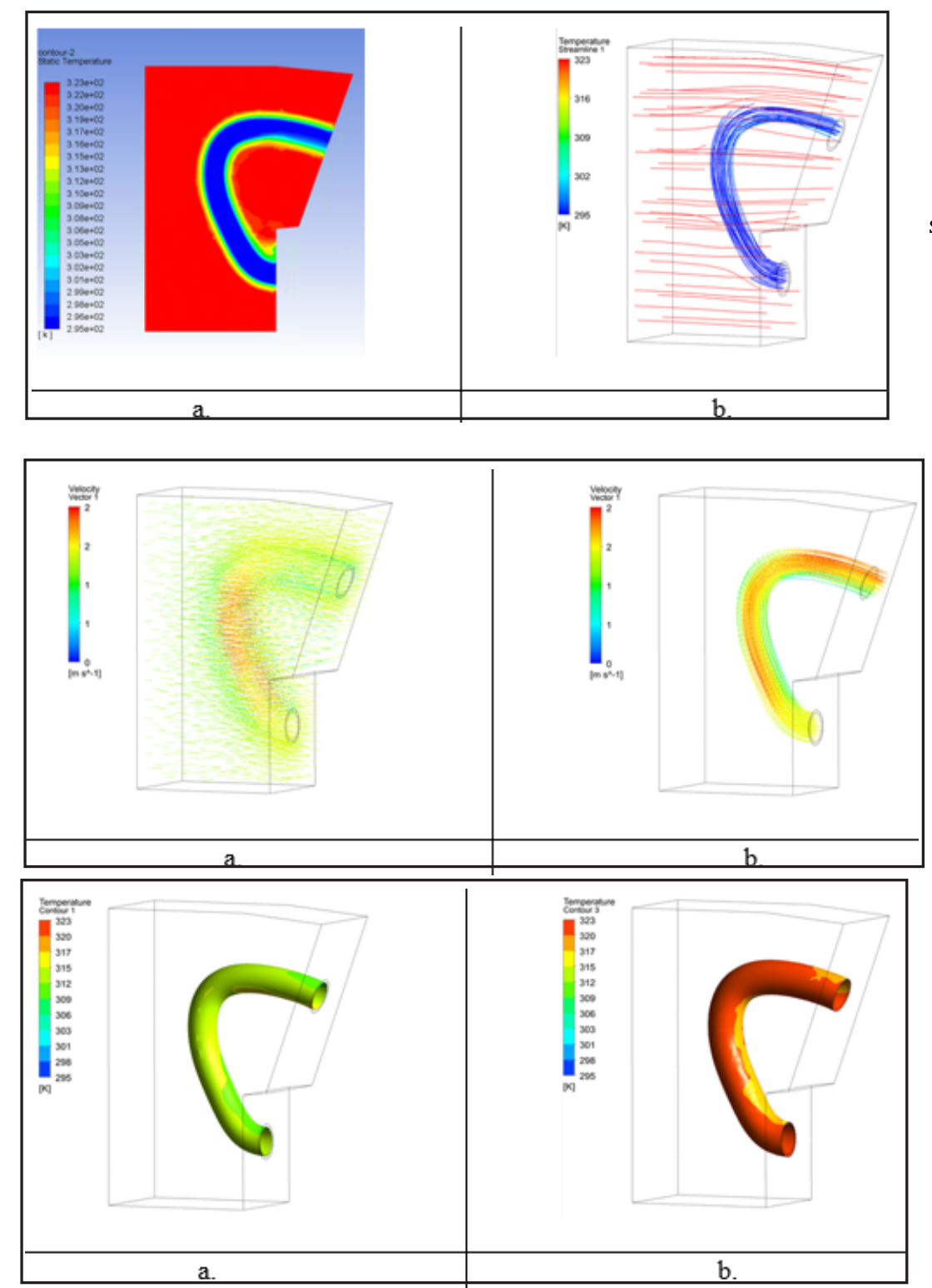

MATERIALE PLASTICE $\bullet 56$ No. 1 \$ $2019 \quad$ http://www.revmaterialeplastice.ro
Fig.e. 8. Temperature field on a median section plane (a) and current lines colorcoded depending on temperature (b)

Fig.. 9. Velocity vectors in the outside (a) and inside of the pipe (b)

Fig.. 10. Distribution of temperatures on the inner (a) and outer (b) surface of the pipe 
Research into the influence of air intake temperature on fuel consumption reveals that a highest value of brake specific fuel consumption (BSFC) was $380 \mathrm{~g} / \mathrm{kW}$.hr at higher air intake temperature $30^{\circ} \mathrm{C}$, which was $4 \%$ higher than the lowest air intake temperature $20^{\circ} \mathrm{C}$ at the same engine speed of $1500 \mathrm{rpm}$. The higher air intake temperature resulted in lower oxygen concentration will lead to a small negative effect on the combustion rate and BSFC [18].

\section{Conclusions}

The objective of the present study was to model the steady state heat transfer of the engine intake system through the temperature and flow rate measurements in the intake manifold model. The important conclusions obtained from this study were summarized below.

The numerical model developed in ANSYS allows the study of the heat transfer regime taking into account the characteristics of the material of the intake manifold in particular by the specific heat transfer coefficient.

The data obtained allows new solutions to be found for the thermal optimization of air interaction with the intake manifold walls, in particular to reduce its heating over the intake path.

The low thermal conductivity coefficient of PA 66 keeps the temperature of the intake air relatively constant, with positive consequences on the cylinder filling efficiency. It can also be seen that the difference in temperature between the inner and outer surface of the pipe wall differs greatly, due to the fact thatPA 66 is a good thermal insulator.

\section{References}

1.***Global Automotive Plastics Industry 2014-2019: Trend, Forecast, and Opportunity Analysis, June 2014

2.PINCA-BRETOTEAN, C., LUCIAN CRACIUN, A.L., JOSAN, A., ARDELEAN, E., Experimental study of sintered friction material with coconut fiber for brake pads, Mat. Plast, 55, no. 3, 2018, p.389-392 3.BEJ , A., BORDEASU, I., MILOS, T., BADARAU, R., Considerations Concerning the Mechanical Strength of Wind Turbine Blades made of Fiberglass Reinforced Polyester, Mat. Plast.,49, no.3, 2012, p..212-218 4.PETRE, R., ZECHERU,T., PETREA, N., GINGHINA, R., SANDU, S., MURESAN, M., MATACHE, L.C., SAVA, A.C., NEATU,F., Synthesis and mechanical properties of polyurea-based hybrid, composites for ballistic individual protection, Mat. Plast, 55, no.3, 2018, p.315-319
5.CAPLESCU, C., MARSAVINA, L., BORDEASU, I., SECHEI, R., M., The Fracture of Polyurethane Materials in the Presence of Stress, Concentrators, Mat. Plast., 47, no.3, 2010, p.379

6.STEFANESCU, V., BOBOC, A., COJAN, A., BOSOANCA, R., MUNTENITA, C., BUNEA, M., The thermal behavior of Hybrid fabric reinforced composites with stratified filled epoxy matrix, Mat. Plast. 55, no.2, 2018, p.161-16

7.LAZAR, I., BORDEASU, B., CIRCIUMARU, A., MITELEA, I., BOCII, L.S., Behavior of polymer thin films deposed on bronze surfaces at cavitation erosion, Rev. Chim. (Bucharest), 69, no. 10, 2018, p. 29212927

8.***Plastics and Polymer Composites in Light Vehicles, Economics \& Statistics Department American Chemistry Council, July 2018

9.SUZUKI, K., MIYAZAKI, T., NEMOTO, M., MACHIDA, K., Optimum Control of Spark Ignition Timing in a Gasoline Engine Using Model Based Methodology, Proc. 2005 J SAE Autumn Convention, Paper No. 20055773, 2005

10.ICHIYANAGI, M., SUZUKI, T., Implementation of Air-Fuel Ratio FeedForward Controller Considering Heat Transfer at Intake System to SI Engine, SAE Tech. Paper, Paper No. 2015-01-1982, 2015

11.ICHIYANAGI, M., KIMURA, T., SUZUKI, T., Development of Engine Control System for Air-to-Fuel Ratio Using Heat Transfer Model at Intake System, Proc. of Int. Forum Heat Trans. 2016

12.ICHIYANAGI, M., TAKARA, S., SUZUKI, T., Reduction Method of Combustion Fluctuation Using Estimation Technique of Maximum InCylinder Pressure of Internal Combustion Engine, Proc. of Int. Forum Heat Trans. 2016

13.SCHUROV, S.M., COLLINGS, N., A Numerical Simulation of Intake Port Phenomena in a Spark Ignition Engine Under Cold Starting Conditions, SAE Tech. Paper, Paper No.941874,1994

14.SHAYLER,P.] ., COLECHIN, M.J.F., SCARISBRICK, A., Heat Transfer Measurements in the Intake Port of a Spark Ignition Engine, SAETech. Paper, Paper No. 960273, 1996

15.WIMMER, A., PIVEC, R., SAMS, T., Heat Transfer tothe Combustion Chamber and Port Walls of IC Engines-Measurement and Prediction, SAE Tech. Paper, Paper No.2000-01-0568,2000

16.DEPCIK, C., ASSANIS, D., A Universal Heat Transfer Correlation for Intake and Exhaust Flows in An Spark-Ignition Internal Combustion Engine, SAETech. Paper, Paper No.2002-01-0372, 2002

17.***ANSIS Homepage, https://www.ansys.com/products

18.ABDULLAH, N. R., ISMAIL, H., ZENO M., RAHIM, A., SHARUDIN, H., Effects of air intake temperature on the fuel consumption and exhaust emissions of natural aspirated gasoline engine, Jurnal Teknologi Sciences \& Engineering elSSN 2180-3722, 2015, p 25.

Manuscript received: 8.12. 2018 